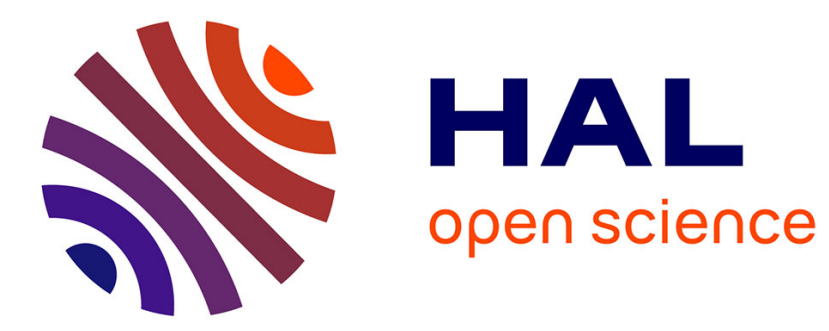

\title{
How to manage a small-scale multi-use forest?
}

Patrice Loisel, Bernard Elyakime

\section{To cite this version:}

Patrice Loisel, Bernard Elyakime. How to manage a small-scale multi-use forest?. Journal of Forest Economics, 2018, 32, pp.13-17. 10.1016/j.jfe.2018.02.003 . hal-02621728

\section{HAL Id: hal-02621728 \\ https://hal.inrae.fr/hal-02621728}

Submitted on 26 May 2020

HAL is a multi-disciplinary open access archive for the deposit and dissemination of scientific research documents, whether they are published or not. The documents may come from teaching and research institutions in France or abroad, or from public or private research centers.
L'archive ouverte pluridisciplinaire HAL, est destinée au dépôt et à la diffusion de documents scientifiques de niveau recherche, publiés ou non, émanant des établissements d'enseignement et de recherche français ou étrangers, des laboratoires publics ou privés. 


\title{
How to manage a small-scale multi-use forest ?
}

Patrice Loisel

MISTEA, INRA, Montpellier SupAgro, Univ Montpellier, Montpellier, France

e-mail : patrice.loisel@inra.fr

Bernard Elyakime

LEF, INRA, AgroParisTech, Nancy, France

e-mail : bernard.elyakime@inra.fr

Corresponding author : Patrice Loisel

\begin{abstract}
The management of a multiple-use and small-scale forest generating merchantable household forest amenities, as mushroom amenities, is studied. We consider a wooded mushroom area and a timber area in the forest. An Hartman model, with an environmental dependency of the amenity area is considered. Optimal timber and non-timber cutting ages and optimal proportion of amenity area are derived. Their behaviours in particular with respect to the market amenity unit value are studied. Moreover an oscillating seasonal amenity production, as the mushroom production, is derived and studied in relation with the optimal tree cutting ages.
\end{abstract}

Keywords : Hartman criterion ; forest management ; household forest amenity ; environmental quality; optimal tree cutting age

JEL Classification : Q23, Q57 


\section{Introduction}

Because forest is a natural habitat of various fauna and flora (e.g. Larrieu and Cabanettes, 2012), forest management could take into account various ecosystem services (e.g. Susaeta et al., 2013). As in the ecosystem approach, the economic representation of a forest by Faustmann (1849) and Hartman (1976) considers various financial forest flows. The Faustmann and Hartman models make it possible to design a silviculture in most European small-scale forests that are under-exploited (Schlueter 2008). This silviculture will encourage trees and household forest amenities : many trees left standing alone are cleared (without carrying out costly thinning operations done on the whole forest) and are likely to constitute many spots of natural habitats for various forest species, so generating positive and valuable amenities such as mushrooming, (e.g. Sourdril et al., 2012, Zotti et al., 2014). Optimal allocation of forest soil for timber production or non-wood production is important in some cases. The owner of a forest specifically dedicated to timber production will not be as sensitive on this question as a non-industrial forest owner. The non-industrial forest owner, specifically farmer forest owner, notably studied by Newman and Wear (1993), Amacher et al. (2003), Lidestav and Nordfjell (2005), Bolkesjø et al. (2007), Sourdril et al., (2012), will be interested in supporting the forest amenities. This forest owner could preserve and even increase the multi-functionality of his/her forest management by creating, preserving or extending small spots, dedicated to mushrooms or other household and valuable forest amenities. He/She would then design a mixed commercial and household forest management dedicated to additional incomes as in French forest farmers for example, Sourdril et al., (2012). This type of forest is of significant interest in France, Le Jeannic et al. (2015), as well as in Finland, Hyttinen and Kolat (1995), or in Australia, Robins et al.(1996). In this last country, farm forestry is increasingly promoted as a land-use option for "improving the viability of agriculture, developing additional timber resources for industry, and enhancing regional development", Race et al. (1998).

This paper is focused on optimal management of a multiple-use small-scale forest, with a forest land divided in two areas, a mushroom area and a timber area. Many authors considered ecological or amenities benefits in the management of forest as in Bowes and Krutilla (1989), Swallow and Wear (1993), Swallow et al. (1997), Rose and Chapman (2003) or Touza et al. (2008), Amacher et al. (2009), Amacher et al. (2014). Perrings and Touza-Montero (2004) recalled how the forest ecological interactions were considered in the literature, regarding the benefits from timber harvesting but also the benefits from the non-wood products. Moreover, Vincent and Binkley (1993) but also e.g. Swallow et al. (1997) or Perrings and Touza-Montero (2004) highlighted the importance of spatialization in forest management : Vincent and Binkley (1993) sought to prove that an effective forest multi-functionality led to a forest spatialised management. Forest land allocation at the stand level is then a small-scale forest multi-use management topic. So, determining optimal land use allocation between timber and mushroom amenity suggests the need for rational decision making, e.g. Hyde (1980), Parks and Murray (1994).

From the literature, two topics are retained. Firstly, the effect of the market amenity unit value on the optimal timber cutting age is not always taken into account, Brazee (2006). But, Koskela and Ollikainen (2001) studied a first approach of this effect. Secondly, if a forest owner 
chose an allocation of his forest soil, for the timber production and e.g. the forest mushroom production, the effect of this mushroom amenity value on the optimal tree cutting age must be studied in the timber area and in the amenity area.

The following questions are studied : what are the optimal tree cutting ages in timber and mushroom areas and what are the behaviours of these optimal tree cutting ages with respect to the market mushroom value in the studied multiple-use small-scale forest model ? Moreover, what is the optimal proportion of mushroom amenity and timber areas with respect to the market mushroom value ? Then, what are the behaviours of the optimal tree cutting ages and of the area proportion dedicated to the mushroom amenity with respect to the total area of the multiple-use small-scale forest?

We consider the case of marketable natural amenities as mushrooms in a multiple-use smallscale forest. Considering the mushroom production, the quality of the biotope will be taken into account : we consider the physical environmental quality which mainly impacts biotope. Due to a supposed good mushrooming environmental quality in a specific area of stand forest, the total forest area is dedicated to timber production and to mushroom production. Moreover, values of timber and mushroom must be considered, Deegen et al. (2011). In the same way, different tree cutting ages also must be taken into account, Coordes (2016). In the first section, we study comparative statics considering the optimal timber and non-timber cutting ages and of the area proportion dedicated to the mushroom amenity with respect to known market value of this amenity. We also clarify the behaviours of the optimal tree cutting ages and of the area proportion dedicated to the mushroom amenity with respect to the total area of the small-scale forest. In the second section, the seasonal characteristic of the amenity is considered to analyse and complete the results of the previous section. Then all results are discussed before concluding.

\section{Management of a multiple-use small-scale forest with na- tural mushroom amenity area}

We consider a forest including specified amenity area. Amenity supplies are assumed to be produced in specific and natural weakly wooded area dedicated to mushroom amenity, Sourdril and al. (2012). The forest has a financial timber value (which leads to the classical forest owner's Faustmann value up to the constant regeneration cost) and in addition has at any time the mushroom amenity revenue (which leads to the forest owner's amenity value). We consider a multi-use forest with an area $S$. We assume that mushroom amenity only depends on forest age and environmental quality.

Let $x$ the proportion of the forest area with mushroom amenity, $S$ the total forest area, $s=S x$ is the forest area with amenity.

The commercial timber is produced in the proportion $1-x$ of forest area. Due to small quantities of woods harvested in a small-scale forest, harvesting costs and regeneration costs per ha are higher than in a large-scale forest (average fixed costs are supposed large as costs of setting up storage places for timbers, Bourcet et al. 2007, Elyakime and Cabanettes 2009). So, 
the financial timber income (the owner's residual timber value) is lower in a small-scale forest. In accordance with the previous hypotheses, the regeneration cost per area unit $c$ in the timber area satisfies $c_{S}^{\prime}<0, c_{S S}^{\prime \prime}=0$. Moreover, we consider natural regeneration in the mushroom amenity area. The financial timber income per area unit $V(T, S)$ depends on the cutting age and the timber area and satisfies $V_{S}^{\prime}>0$ and $V_{T S}^{\prime \prime}=V_{S S}^{\prime \prime}=0$.

Contrary to the classical Hartman approach, we assume different tree cutting ages, respectively for the wooded mushroom amenity area and for the timber area. Moreover, due to a supposed interdependency between tree and amenity ${ }^{1}$, we consider a stylised Hartmann model : the wooded amenity area is assumed not to produce commercial wood and the timber area is assumed not to produce merchantable amenity. So, the forest is evaluated with an alternative Hartman value, considering specific cutting age $T_{w}$ for Faustmann value and $T_{a}$ for amenity value :

$$
H\left(S, x, T_{a}, T_{w}\right)=S x E\left(T_{a}, x\right)+S(1-x) J\left(T_{w}, S(1-x)\right)
$$

with the Faustmann value $J(T, s)=\frac{V(T, s)-c(s) e^{\delta T}}{e^{\delta T}-1}$ and the amenity value $E(T, x)=$ $\frac{A \int_{0}^{T} F(t, x) e^{\delta(T-t)} d t}{e^{\delta T}-1}$ per area unit, where $A$ is the market amenity unit value, $F(t, x)$ is a marginal characteristic of amenities at time $t$ per area unit (hypotheses on marginal function $F$ will be specified later).

The amenity benefits depend on the forest age and the environmental quality. We assumed that environmental quality has a larger impact on amenity than on timber areas, so we neglect the impact of environmental quality in the timber area. The mushroom amenity area is assumed preferentially located in high environmental quality area. Let $Q$ the distribution of the environmental quality in the total area with support $[q, \bar{q}]$, hence the proportion of amenity area $x$ corresponds to area where the environmental quality is greater that a value $q_{e}$ :

$$
x\left(q_{e}\right)=\int_{q_{e}}^{\bar{q}} d Q(q)=1-Q\left(q_{e}\right)
$$

Moreover, we assume that each environmental quality $q_{e}$ leads to a production rate $r\left(q_{e}\right)$ with increasing $r$ with respect to $q_{e}$ (i.e. $r^{\prime}\left(q_{e}\right) \geq 0$ ) and $r\left(\bar{q}_{e}\right)=1$. We assume that the marginal amenity function is separable in forest age and environmental quality $q_{e}$ :

$$
F\left(t, x\left(q_{e}\right)\right)=\Gamma\left(x\left(q_{e}\right)\right) F_{0}(t)
$$

where $\Gamma\left(x\left(q_{e}\right)\right)$ is the expectation of production rate : $\Gamma\left(x\left(q_{e}\right)\right)=\frac{\int_{q_{e}}^{\bar{q}} r(q) d Q(q)}{\int_{q_{e}}^{\bar{q}} d Q(q)}$. With the assumed hypotheses on $r$ behaviour, $\Gamma(0)=1, \Gamma$ is decreasing, $x \Gamma(x)$ is increasing and concave with respect to the proportion of amenity area $x$ and the amenity production per area unit is also separable :

$$
E(T, x)=\Gamma(x) E_{0}(T, x) \text { with } E_{0}(T, x)=A \frac{\int_{0}^{T} F_{0}(t) e^{\delta(T-t)} d t}{e^{\delta T}-1}
$$

1. These interdependencies are not explicitely taken into account because we do not study the forest management tree by tree as in Coordes (2016). 
Taking into account the endogeneous proportion of amenity area, we consider the forest management with respect to the cutting age and the proportion of amenity area. From the form of marginal amenity function (1) the derivative $H_{T_{a}}(T)$ of the Hartman Value with respect to the cutting age in the amenity area $T_{a}$ may be deduce :

$$
\begin{aligned}
\left(e^{\delta T_{a}}-1\right)^{2} H_{T_{a}}\left(T_{a}\right) & =S x\left[A \Gamma(x)\left(F_{0}\left(T_{a}\right)\left(e^{\delta T_{a}}-1\right)-\delta \int_{0}^{T_{a}} F_{0}(t) e^{\delta\left(T_{a}-t\right)} d t\right)\right] \\
& =S x \delta\left[A \Gamma(x) \int_{0}^{T_{a}}\left(F_{0}\left(T_{a}\right)-F_{0}(t)\right) e^{\delta\left(T_{a}-t\right)} d t\right] \\
& =S \delta A x \Gamma(x) B_{F_{0}}\left(T_{a}\right)
\end{aligned}
$$

where the function $B_{F}$ is defined by :

$$
B_{F}(T)=\int_{0}^{T}(F(T)-F(t)) e^{\delta(T-t)} d t
$$

Hence to each marginal amenity function $F$ we associate the cumulative amenity function $B_{F}$. We thus deduce :

Proposition 2.1 Assumed that the marginal amenity function is separable in forest age and environmental quality then the optimal cutting age in the amenity area $T_{a}$ is independent of the market amenity unit value A. Moreover:

(i) If $B_{F_{0}}(T)>0$ for all cutting age $T$ then the tree cutting age in the amenity area is only limited by senescence : the optimal cutting age $T_{a}$ is the tree-senescence.

(ii) If it exists a cutting age $T_{*}$ such that $B_{F_{0}}(T)>0$ (resp. $\left.<0\right)$ for $T<T_{*}$ (resp. $\left.>T_{*}\right)$, then the optimal cutting age $T_{a}$ in the amenity area is equal to $T_{*}$.

Proof: The derivative of Hartman Value with respect to cutting age in the amenity area is proportional (with the same sign) that : $B_{F_{0}}\left(T_{a}\right)$, hence the result

The expression $B_{F}(T)=\left(e^{\delta T}-1\right)(F(T)-\delta E(T, 0))$ and $B_{F}(T)>0$ involve an amenity marginal gain greater than the corresponding financial opportunity cost.

Moreover, we obtain the behaviour of the optimal proportion of amenity area and the optimal cutting age in the timber area :

Proposition 2.2 Assume that the marginal amenity function is separable in forest age and environmental quality, an interior optimal proportion of amenity area $x(0<x<1)$ then the optimal proportion of amenity area $x$ and the optimal cutting age in the timber area $T_{w}$ increase with respect to the market amenity unit value $A$.

The Proof of this Proposition is given in Annex A.

Remark : the Hartman's optimal cutting age $T_{w}$ is also the Faustmann's optimal cutting age for a modified area $S(1-x)$. 
As the average surface of the small-scale forest is variable from a country to another (e.g. Wiermsum et al., 2005, European Forest Institute, 2015), we now consider the behaviour of optimal timber cutting age and area proportion with respect to area $S$ :

Proposition 2.3 Assuming that the marginal amenity function is separable in forest age and environmental quality, an interior optimal proportion area $x$, then the optimal cutting age $T_{a}$ is independent of the total area $S$, the optimal proportion area $x$ and the optimal cutting age in the timber area $T_{w}$ decrease with respect to total area $S$, the distribution of the environmental quality remains unchanged.

The Proof of this Proposition is given in Annex B.

The more the small-scale forest area decreases, the more the optimal proportion area $x$ and the optimal timber cutting age grow, timber costs of harvesting and of renegeration growing.

We underline that the physical marginal gain $\left[x \Gamma^{\prime}(x)\right]^{\prime}$ is equal to the ratio of the timber/amenity incomes $\frac{J\left(T_{w}, S(1-x)\right)+(1-x) J_{S}^{\prime}\left(T_{w}, S(1-x)\right)}{E\left(T_{a}, 1\right)}$.

Remark : for non natural regeneration, we can introduce regeneration cost, but the behaviour of $T_{a}$ with respect to $A, x$ or $S$ is is unknown and must studied for each practical case.

Furthermore, we underline that these results are relevant for any marketable amenity within the framework of the model assumptions.

\section{Management of oscillating amenities}

To deal in depth with the small-scale forest multifunctional management, we have considered a complex forest mushroom amenity. This amenity has seasonal oscillations, successively increasing and decreasing. It is then shown that the approach of the previous section includes the management of this type of amenity by deriving the oscillating function $F$.

Firstly, as the sign of this function $B_{F}$ governs the behaviour of the optimal cutting age in the mushroom amenity area, we study the link between the marginal amenity function $F$ and the cumulative amenity $B_{F}$ :

Proposition 3.1 Assuming, the marginal amenity function $F$ continuous, then :

- the associated cumulative amenity function $B_{F}$ satisfies $B_{F}(0)=0, B_{F}(T) / T^{2}$ is integrable in the vicinity of $T=0$.

- the formula (3) which gives $B_{F}$ as function of $F$, is invertible :

$$
F(T)=F(0)+\mathcal{A}\left(B_{F}\right)(T)
$$

where the operator $\mathcal{A}$ is defined for all functions $G \geq 0$ and $G(T) / T^{2}$ integrable in the vicinity of $T=0$ by

$$
\mathcal{A}(G)(T)=\delta \frac{G(T)}{e^{\delta T}-1}+\delta^{2} \int_{0}^{T} \frac{G(t)}{\left(e^{\delta t}-1\right)^{2}} d t
$$


The proof of Proposition is given in Annex C. So from cumulative amenity function $G$, we deduce the expression of the associated marginal amenity function, hence the behaviour of the Hartman Value with the associated marginal amenity function $F$.

Secondly, from the expression of $B_{F}$ we deduce that behaviours of functions $F$ and $B_{F}$ are inter-related :

Proposition 3.2 The functions $F$ and $B_{F}(T) e^{-\delta T}$ have the same behaviour with respect to the age $T$.

Proof: Assume, for example the function $F$ increasing on an interval $I$, i.e. $F(t)-F(s)>0$ for all $s, t \in I$ with $s<t$ then :

$$
\begin{aligned}
& \delta\left(B_{F}(t) e^{-\delta t}-B_{F}(s) e^{-\delta s}\right)=F(t)\left(1-e^{-\delta t}\right)-F(s)\left(1-e^{-\delta s}\right)-\delta \int_{s}^{t} F(u) e^{-\delta u} d u \\
& >F(t)\left(1-e^{-\delta t}\right)-F(s)\left(1-e^{-\delta s}\right)-F(t)\left(e^{-\delta s}-e^{-\delta t}\right)=(F(t)-F(s))\left(1-e^{-\delta s}\right)>0
\end{aligned}
$$

Reversely, if $\delta B_{F}(t) e^{-\delta T}$ is increasing, from Equation (4) we deduce that $F$ is increasing.

Then, using Equation (4) we may consider a positive cumulative amenity function $B_{F}$ which generates a marginal mushroom amenity stylised function $F$ successively increasing and decreasing. For example if we consider oscillating amenities such that $F^{\prime}(T)=\delta G_{0} \omega \frac{\sin (\omega T)}{1-e^{-\delta T}}$ changes sign all the more frequently as $\omega$ is high. The corresponding overall amenity $B_{F}(T)=$ $G_{0}(1-\cos (\omega T)) e^{\delta T}$ remains positive. For moderate values of $\omega$, this corresponds to seasonal amenities. The case of the stylised function $F$ is illustrated in Figure 1.

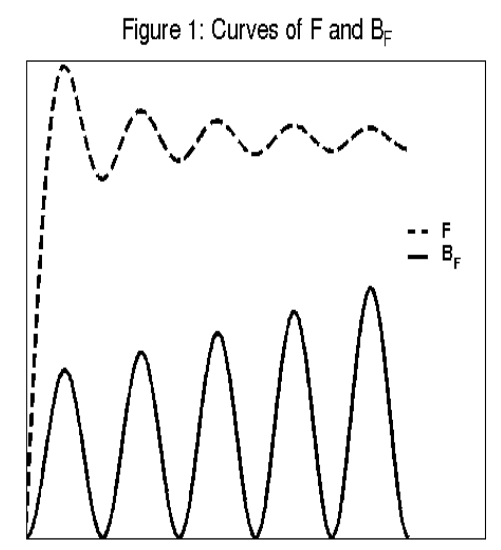

We thus showed the importance of the sign of mushroom amenity cumulative function $B_{F}$ to predict the behaviour of the optimal tree cutting age in the production area of the mushroom amenity. Even if the marginal function of the mushroom amenity is oscillating, the corresponding cumulative function $B_{F}\left(T_{a}\right)$ can remain positive in certain cases. This specificity implies that the optimal tree cutting age in the mushroom amenity area production is, in this case, only limited by the senescence of the trees according to Proposition 2.1. 


\section{Discussion}

Our results concern the management of a mutiple-use small-scale forest. We have considered a forest including mushroom amenity area in natural weakly wooded spots. Moreover, we assumed that amenities only depend on forest tree age and environmental quality in the amenity area.

Propositions 2.1, 2.2 and 2.3 are related to the management of the timber production and the amenity production in the multiple-use small-scale forest. The way the mushroom amenities are produced results in a slightly different standard Hartman criterion. Propositions 3.1 and 3.2 apply to an oscillating amenity production such as the mushroom production. They study the existence of a cumulative function of this kind of amenity and the consequences of its behaviour.

Considering Proposition 2.2, (1) the optimal timber cutting age in the timber area increases regarding the market amenity value : more proportion of surface devoted to mushroom amenity (due to a higher market amenity value) induces more amenities values that implies less owner's residual net timber values and thus consequently a focus on higher timber production. (2) But in the mushroom amenity area, the optimal tree cutting age is not dependent on the market amenity value. It depends on either only the tree senescence or the behaviour of the cumulative amenity function. Propositions 3.1 and 3.2 also prove the relevance of the study of the cumulative amenity function behaviour for a specific seasonal amenity function.

Compared to the results of Parks and Murray (1994) and regarding optimal tree cutting ages in timber and mushroom amenity areas, our approach produces new results given in Proposition 2.1. This approach underlines a management specificity (with a marginal amenity function separable in forest age and environmental quality) in the studied multiple-use small-case forest compared to Koskela and Ollikainen's results (2001).

Regarding Proposition 2.3, the more the small-scale forest area increases, the more the optimal timber cutting age decreases, the cost of timber harvesting decreasing. This last result is in conformity with Amacher et al. (2009) results considering the influence of harvesting costs.

In addition, considering Proposition 2.2 and Proposition 2.3, the proportion of surface devoted to the mushroom amenity grows with the rise of the amenity value. The more the small-scale forest area decreases, timber costs of harvesting and of renegeration grow, hence the more the optimal proportion area devoted to the amenity and the optimal timber cutting age grow. This last result is in conformity with the result of Bowes and Krutilla (1985) who claim an optimum rotation longer than the Faustmann rotation for a wide range of non-timber benefits.

Furthermore, we underline that optimal tree cutting age in the studied multiple-use forest must be computed for each practical case. These results are relevant to any marketable amenity within the framework of the model assumptions. 


\section{Conclusion}

We studied multiple-use small-scale forest management model. We considered a Hartman model for a small-scale forest with natural and environmental dependent mushroom amenity area.

We gave complete results regarding the optimal tree cutting age with respect to the market amenity unit value in environmental dependent multiple-use Hartman model. We also studied the optimal cutting age with respect to the area of the small-scale forest.

To conclude, the management in a multiple-use small-scale forest is flexible. The behaviours of the optimal tree cutting ages with respect to the market mushroom value in the timber area and in the amenity area are different. Moreover in this amenity area, the optimal tree cutting age is complex, that is to say (1) is not dependent on market amenity unit value (2) is dependent on either only the tree senescence or the cumulative amenity function behaviour. At the stand level, optimal land use allocation between timber and mushroom amenity is derived.

These results could open the door to a specific multifunctional silviculture, that is to say a natural and environmental dependent multiple-use silviculture in small-scale and more specifically in farmers' forests.

\section{A Proof of Proposition 2.2}

The first-order optimality conditions are $H_{T_{w}}=0$ and $H_{x}=0$. We differentiate the firstorder optimality conditions with respect to the market amenity unit value :

$$
\begin{aligned}
H_{T_{w} A}+H_{T_{w} T_{w}} \frac{\partial T_{w}}{\partial A}+H_{T_{w} x} \frac{\partial x}{\partial A} & =0 \\
H_{x A}+H_{x T_{w}} \frac{\partial T_{w}}{\partial A}+H_{x x} \frac{\partial x}{\partial A} & =0
\end{aligned}
$$

The condition $H_{T_{w}=0}$ gives : $J_{T}^{\prime}\left(T_{w}\right)=0$ and the condition $H_{x}=0$ gives : $S[x \Gamma(x)]^{\prime} E_{0}\left(T_{a}\right)-$ $S J\left(T_{w}\right)-S(1-x) J_{s}^{\prime}\left(T_{w}\right)=0$. The second derivatives $H_{x A}$ and $H_{T_{w} x}$ are respectively proportional to and have the same sign as : $[x \Gamma(x)]^{\prime} E_{0}\left(T_{a}\right)$ and $(1-x)\left(V_{S}^{\prime}\left(T_{w}\right)-c_{S}^{\prime}\right)(>0)$ and $H_{T_{w} A}=0$. As $\frac{\partial T_{w}}{\partial A}$ and $H_{x A} H_{T_{w} x}$ have the same sign, $\frac{\partial T_{w}}{\partial A}>0$. From second-order optimality conditions $H_{T_{w} T_{w}}<0$, as $\frac{\partial x}{\partial A}$ and $H_{x A} H_{T_{w} T_{w}}$ have opposite sign, $\frac{\partial x}{\partial A}>0$.

\section{B Proof of Proposition 2.3}

Similarly to proof of Proposition 2.2, we note that $H_{T_{w} S}$ is proportional and have the same sign as : $-(1-x)^{2}\left(V_{S}^{\prime}\left(T_{w}\right)-c_{S}^{\prime}\right)$ hence $H_{T_{w} S}$ and $H_{T_{w} x}$ are of opposite sign. Moreover $H_{x S}$ is proportional and have the same sign as : $-(2-x)\left(V_{S}^{\prime}\left(T_{w}\right)-c_{S}^{\prime} e^{\delta T_{w}}\right)$ hence $H_{x S}$ is negative. 
From second-order optimality conditions $H_{T_{w} T_{w}}, H_{x x}<0, \frac{\partial T_{w}}{\partial S}$ and $\frac{\partial T_{w}}{\partial S}$ have respectively the same sign as $H_{T_{w} x} H_{x S}-H_{x x} H_{T_{w} S}$ and $H_{T_{w} x} H_{T_{w} S}-H_{T_{w} T_{w}} H_{x S}$ so $\frac{\partial x}{\partial S}<0$ and $\frac{\partial T_{w}}{\partial S}<0$.

\section{Proof of proposition 3.1}

We consider a function $G$ with $G(0)=0$ and we search for a function $F$ satisfying :

$$
\begin{aligned}
F(T)\left(1-e^{-\delta T}\right)-\delta \int_{0}^{T} F(t) e^{-\delta t} d t & =\delta G(T) e^{-\delta T} \\
\frac{(F(T)-F(0)) e^{-\delta T}\left(1-e^{-\delta T}\right)-\delta e^{-\delta T} \int_{0}^{T}(F(t)-F(0)) e^{-\delta t} d t}{\left(1-e^{-\delta T}\right)^{2}} & =\delta \frac{G(T) e^{-2 \delta T}}{\left(1-e^{-\delta T}\right)^{2}} \\
{\left[\frac{\int_{0}^{T}(F(t)-F(0)) e^{-\delta t} d t}{1-e^{-\delta T}}\right]^{\prime} } & =\delta \frac{G(T) e^{-2 \delta T}}{\left(1-e^{-\delta T}\right)^{2}}
\end{aligned}
$$

hence $G(T) / T^{2}$ is integrable in the vicinity of $T=0$, so by integration and differentiation :

$$
\begin{aligned}
\int_{0}^{T}(F(t)-F(0)) e^{-\delta t} d t & =\delta\left(1-e^{-\delta T}\right) \int_{0}^{T} \frac{G(t) e^{-2 \delta t}}{\left(1-e^{-\delta t}\right)^{2}} d t \\
F(T)-F(0) & =\left[\left(1-e^{-\delta T}\right) \int_{0}^{T} \frac{G(t) e^{-2 \delta t}}{\left(1-e^{-\delta t}\right)^{2}} d t\right]^{\prime} \delta e^{\delta T}
\end{aligned}
$$

so we deduce the result.

\section{References}

Amacher G.S., Conway M.C. and J. Sullivan. 2003. Econometric analyses of nonindustrial forest landowners : Is there anything left to study? Journal of Forest Economics, 9, 137-164.

Amacher G.S., Ollikainen M. and E. Koskela. 2009. Economics offorest ressources. The MIT Press Cambridge, Massachusetts London, England.

Amacher G.S., Ollikainen M. and J. Uusivuoiri. 2014. Forests and ecosystem services, Outlines for new policy options. Forest Policy and Economics, 47, 1-3.

Bolkesjø T.F., Solberg B. and K.R. Wangen. 2007. Heterogeneity in nonindustrial roundwood supply : Lessons from a large panel of forest owners. Journal of Forest Economics, 13, 7-28.

Bourcet J., Robert P. and A. Zeller. 2007. Audit de la forêt privée sur la première mise en marché des bois. CGAER 1217, 58 p.

Bowes M.D. and J.V. Krutilla. 1989. Multiple use management : the economics of public forestlands. J. Hopkins University Press.

Brazee R.J. 2006. The Faustmann face of optimal forest harvesting. In The International Yearbook of Environmental and Resource Economics, T. Tietenberg and H. Folmer, New Horizons in Environmental Economics. Edward Elgar, UK, USA. 
Coordes R. 2016. The emergence of forest age structures as determined by uneven-aged stands and age class forests. Journal of Forest Economics, 25, 160-179

Deegen P., Hostettler M. and G., Navarro G. 2011. The Faustmann model as a model for a forestry of prices. European Journal of Forest Research 130(3), 353-368.

Elyakime B. and A. Cabanettes. 2009. How to improve the marketing of timber in France ? Forest Policy and Economics, 11 (3), 169-173.

European Forest Institute. 2015. Forest Land Ownership Change in Europe. EFISE Research Report. University of Natural Resources and Life Sciences, Vienna (BOKU).

Faustmann M. 1849. Berechnung des Wertes Wadboden sowie noch nicht haubare Holzbestande für die Waldwirtschaft besitzen, Allgemeine Forst und Jagd-Zeitung, 25, 441-455.

Hartman R. 1976. The harvesting decision when a standing forest has a value, Economic Inquiry, $14,52-58$.

Hyde W.F. 1980. Timber supply, land allocation and economic efficiency. Ressources For the Future. New York. London.

Hyttinen P. and J. Kolat. 1995. Farm Forests and Rural Livelihood in Finland. Journal of Rural Studies. 11-4, 387-396.

Koskela E. and M. Ollikainen. 2001. Forest Taxation and Rotation Age under Amenity Valuation : New Results. Journal of Environmental Economics and Management, 42, 374-384.

Larrieu L. and A. Cabanettes. 2012. Species, live status, and diameter are important tree features for diversity and abundance of tree microhabitats in subnatural montane beech-fir forests. Canadian Journal of Forest Research, 42, 1433-1445.

Le Jeannic F., Thivolle-Cazat A. and L. Guinard. 2015. La forêt privée franaise en France métropolitaine : structure, propriétaires et potentiel de production. Agreste Les Dossiers, Ministère de l'Agriculture de l'Agroalimentaire et de la Forêt

Lidestav G. and T. Nordfjell. 2005. A conceptual model for understanding social practices in family forestry. Small-scale Forest Economics, Management and Policy, 4(4), 391-408.

Newman, D.H. and D.N. Wear. 1993. Production economics of forestry : a comparison of industrial and nonindustrial forest owners. American Journal of Agricultural Economics, 75(3), 674-684.

Parks P.J. and B.C. Murray. 1994. Land Attributes and Land Allocation : Nonindustrial Forest Use in the Pacific Northwest. Forest science, 40-3,558-575.

Perrings C. and J. Touza-Montero. 2004. Spatial interactions and forest management : policy issues. In Horne, Paula, Tönnes, Susan and Koskela, Terhi (eds.) Proceedings of the Conference on Policy Instruments for Safeguarding Forest Biodiversity. Legal and Economic Viewpoints. METLA : 15-24.

Race D., Guijt I. and P. Kanowski. 1998. Australian experiences of farm forestry. Environmental Conservation, 25(3), 234 ?243. 
Robins, L., Mc Intyre, K. and J. Woodhill. 1996. Farm Forestry in Australia : Integrating commercial and Conservation Benefits. Greening Australia Ltd, Canberra, ACT, Australia.

Rose S.K. and D. Chapman. 2003. Timber harvest adjacency economies, hunting, species protection, and old growthvalue : seeking the dynamic optimum? Ecological Economics, 44, 325-344.

Schlueter A. 2008. Small-scale European forestry, an anticommons ? International Journal of the commons, 2 (2), 248-268.

Sourdril A., Andrieu E., Cabanettes A., Elyakime B. and S. Ladet. 2012. How to Maintain Domesticity of Usages in Small Rural Forests? Lessons from Forest Management Continuity through a French Case Study. Ecology and Society 17 (2),6.

Susaeta A., Chang S.J., Carter D.R. and P. Lal. 2013. Economics of carbon sequestration under fluctuating economic environment, forest management and technological changes: An application to forest stands in the southern United States. Journal of Forest Economics 20(1), 47-64.

Swallow S.K. and D.N. Wear. 1993. Spatial Interactions in Multiple-Use Forestry and Substitution and Wealth Effects for the Single Stand. Journal of Environmental Economics and Management, 25, 103-120.

Swallow S.K., Talukdar P. and D.N. Wear. 1997. Spatial and Temporal Specialization in Forest Ecosystem Management under Sole Ownership. American Journal of Agricultural Economics,79, 311-326.

Touza J., Termansen M. and C. Perrings. 2008. A bioeconomic approach to the Faustman-Hartman model : Ecological interactions in managed forest. Natural Resource Modeling. 21 (4), 551-581.

Vincent J.R. and C.S. Binkley. 1993. Efficient Multiple-Use Forestry May Require Land-Use Specialization. Land Economics, 69(4), 370-376.

Wiermsum K.F., Elands B.H.M. and M.A. Hoogstra. 2005. Small-scale forest ownership across Europe : characteristics and future potential. Small-Scale Forest Economics, Management and Policy, 4(1), 1-19.

Zotti M., Ambrosio E., Di Piazza S., Pavarino M., Marrioti M. and P. Marescotti. 2014. La sylviculture comme outil potentiel pour améliorer la production des champignons comestibles : l'expérience dans une forêt du nord-ouest de l'Italie. Colloque sur les champignons forestiers et autres PFNL: innovations et perspectives La Pocatiêre Québec, Canada, 1-28.

http :// www.mycotourismekamouraska.com/pdf/Zotti_et_al.pdf

Acknowledgement

This work was supported by a grant overseen by the French National Research Agency (ANR) as part of the "Investissements d'Avenir" program (ANR-11-LABX-0002-01, Lab of Excellence ARBRE). 